\title{
Long-Term Stable 1-butyl-3-methylimidazolium Hexafluorophosphate/Ag Metal Composite Membranes for Facilitated Olefin Transport
}

\author{
Sang Wook Kang ${ }^{1,2}$ \\ 1 Department of Chemistry, Sangmyung University, Seoul 03016, Korea; swkang@smu.ac.kr; \\ Tel.: +82-2-2287-5362 \\ 2 Department of Chemistry and Energy Engineering, Sangmyung University, Seoul 03016, Korea
}

Received: 21 July 2020; Accepted: 17 August 2020; Published: 18 August 2020

check for updates

\begin{abstract}
For the preparation of long-term stable ionic liquid/Ag nanoparticles composites, we compared the separation performance of 1-butyl-3-methylimidazolium tetrafluoroborate $\left(\mathrm{BMIM}^{+} \mathrm{BF}_{4}^{-}\right) / \mathrm{Ag}$, and 1-butyl-3-methylimidazolium hexafluorophosphate $\left(\mathrm{BMIM}^{+} \mathrm{PF}_{6}{ }^{-}\right) / \mathrm{Ag}$ composite membranes with time. Separation performance showed that the $\mathrm{BMIM}^{+} \mathrm{PF}_{6}{ }^{-} / \mathrm{Ag}$ metal composite membrane was more stable than the $\mathrm{BMIM}^{+} \mathrm{BF}_{4}{ }^{-} / \mathrm{Ag}$ metal composite membrane for more than $160 \mathrm{~h}$. These differences in long-term stability in $\mathrm{BMIM}^{+} \mathrm{PF}_{6}{ }^{-} / \mathrm{Ag}$ and $\mathrm{BMIM}^{+} \mathrm{BF}_{4}{ }^{-} / \mathrm{Ag}$ metal composite membranes was attributable to the phase separation between ionic liquid and nanoparticles. In particular, the phase separation between ionic liquid and silver nanoparticles was not observed with time in hydrophobic ionic liquid $\mathrm{BMIM}^{+} \mathrm{PF}_{6}{ }^{-}$, confirmed by $\mathrm{X}$-ray photoelectron spectroscopy.
\end{abstract}

Keywords: olefin; paraffin; ionic liquid; facilitated transport; membranes

\section{Introduction}

Silver ions can be reversibly reacted with olefin molecules, forming a silver-olefin complex [1-9]. Thus, the silver polymer electrolytes have been investigated as an alternative method in the distillation process, requiring high cost and space [2,4]. For example, the facilitated transport of propylene and ethylene through silver polymer electrolyte membranes consisting of $\mathrm{AgBF}_{4}$ or $\mathrm{AgCF}_{3} \mathrm{SO}_{3}$ dissolved in either poly(2-ethyl-2-oxazoline) (POZ), poly(N-vinyl pyrrolidone) (PVP) and poly(ethylene oxide) (PEO) showed the separation performance of 50 (propylene/propane) in selectivity and $12 \mathrm{GPU}$ ((1 GPU $\left.=1 \times 10^{-6} \mathrm{~cm}^{3}(\mathrm{STP}) /\left(\mathrm{cm}^{2} \mathrm{~s} \mathrm{cmHg}\right)\right)$ in permeance [5]. However, since these metal ion-based systems could be poisoned by $\mathrm{C}_{2} \mathrm{H}_{2}, \mathrm{CO}$, and $\mathrm{H}_{2} \mathrm{~S}$, silver ions were limited in application to the industry field [10]. Furthermore, M. McKenna et al. reported that the sulfur-containing systems might be tolerant to $\mathrm{H}_{2} \mathrm{~S}$ and $\mathrm{CO}$, but would react with $\mathrm{H}_{2}$ and $\mathrm{C}_{2} \mathrm{H}_{2}$ [11]. Therefore, the development of a new olefin carrier for separation of propylene/propane is required.

Recently, our group reported that $\mathrm{Ag}$ nanoparticles polarized by electron acceptors such as $p$-benzoquinone ( $p$-BQ) and 7,7,8,8-tetracyanoquinodimethane (TCNQ) could reversibly interact with olefin molecules such as propylene and ethylene, resulting in the separation performance for olefin/paraffin mixtures [12]. For example, when TCNQ was incorporated into PVP/Ag nanoparticle composites, the selectivity and mixed-gas permeance reached 50 and 3.5 GPU, respectively, for more than $130 \mathrm{~h}$ [12]. On the other hand, $p$-BQ was utilized into relatively flexible PEO matrix with Ag nanoparticles, the mixed-gas selectivity was observed as 10 with 15 GPU for more than $240 \mathrm{~h} \mathrm{[13].}$ When PEBAX-1657/Ag nanoparticle composites with TCNQ were used as polymer membranes, they showed separation performance such as selectivity of 12.7 and permeance of 10.2 GPU [14].

Furthermore, our group reported that ionic liquid also could induce partial positive charges on the surface of silver nanoparticles, reacting reversibly with olefins such as propylene [15]. Such reversible 
interactions in ionic liquids were employed for facilitated olefin transport and membranes for separation of olefin/paraffin mixtures [15]. These results suggest the new use for ionic liquids as polarizers for $\mathrm{Ag}$ nanoparticles in facilitated olefin transport membranes with $p$-BQ. In particular, the strong interaction between the counteranion of ionic liquid and silver nanoparticles caused the surface of the silver metal to be positively charged and was expected to be utilized as liquid-state membranes for adsorbent materials. Since the ionic liquids could play a role as matrix for the preparation of membranes due to relatively high viscosity, they have been widely utilized in liquid-state membranes.

In this paper, we reported the stability of ionic liquid/Ag metal composite membrane and suggested the stable membrane for facilitated olefin transport membrane as well as the long-term stable condition for ionic liquids. In particular, the hydrophilic and hydrophobic ionic liquids such as 1-butyl-3-methylimidazolium tetrafluoroborate $\left(\mathrm{BMIM}^{+} \mathrm{BF}_{4}{ }^{-}\right)$, and 1-butyl-3-methylimidazolium hexafluorophosphate $\left(\mathrm{BMIM}^{+} \mathrm{PF}_{6}{ }^{-}\right)$, respectively, were chosen and compared in viewpoint of the interactions between $\mathrm{Ag}$ particles and ionic liquids (ILs).

\section{Materials and Methods}

\subsection{Materials}

Silver nanopowder $(<100 \mathrm{~nm}, 99.5 \%)$ was purchased from Aldrich Chemical Co (St. Louis, $\mathrm{MO}, \mathrm{USA})$. The ionic liquids 1-butyl-3-methylimidazolium tetrafluoroborate $\left(\mathrm{BMIM}^{+} \mathrm{BF}_{4}{ }^{-}, 98 \%\right)$ and 1-butyl-3-methylimidazolium hexafluorophosphate $\left(\mathrm{BMIM}^{+} \mathrm{PF}_{6}{ }^{-}, 98 \%\right)$ were purchased from C-TRI Co (Gyeonggi-do, Korea). All the chemicals were used as received.

\subsection{Separation Performance}

The ILs/Ag composite membranes were prepared by dispersing Ag nanopowder in ILs. The ILs' weight was fixed at $1 \mathrm{~g}$ and the amount of the Ag nanopowder was varied. For the fabrication of the separation membranes, the mixed solution was coated onto polyester microporous membrane supports (Osmonics Inc., Minnetonka, MN, USA, pore $0.1 \mu \mathrm{m}$ ) using an RK Control Coater (Model 101, Control Coater RK Print-Coat instruments LTD, UK). The solution consisting of ionic liquid and silver nanoparticles could be maintained as the coating layer as it was on the porous polymer support due to its high viscosity. Gas flow rates or gas permeances were measured with a mass flow meter (MFM). The unit of gas permeance is GPU, where $1 \mathrm{GPU}=1 \times 10^{-6} \mathrm{~cm}^{3}(\mathrm{STP}) /\left(\mathrm{cm}^{2} \mathrm{sec} \mathrm{cmHg}\right)$. The mixed gas (50:50 vol \% propylene/propane mixture) separation properties of the ILs/Ag composite membranes were evaluated using a gas chromatograph (Hewlett-Packard G1530A, Palo Alto, CA, USA) equipped with a TCD detector and a unibead $2 \mathrm{~S} 60 / 80$ packed column.

\subsection{Characterization}

X-ray photoelectron spectroscopy (XPS) data were acquired using a Perkin-Elmer Physical Electronics PHI $5400 \mathrm{X}$-ray photoelectron spectrometer (Waltham, Massachusetts, United States). This system was equipped with a $\mathrm{Mg}$ X-ray source operated at $300 \mathrm{~W}(15 \mathrm{kV}, 20 \mathrm{~mA})$. The carbon (C 1s) line at $285.0 \mathrm{eV}$ was used as the reference in our determinations of the binding energies of the silver.

\section{Results}

\subsection{Performance in Separation of Propylene/Propane Mixtures}

The separation of propylene/propane mixtures using $\mathrm{BMIM}^{+} \mathrm{BF}_{4}{ }^{-}$and $\mathrm{BMIM}^{+} \mathrm{PF}_{6}{ }^{-}$membranes was evaluated with varying concentrations of the silver nanoparticles. The $\mathrm{BMIM}^{+} \mathrm{BF}_{4}{ }^{-}$and $\mathrm{BMIM}^{+} \mathrm{PF}_{6}{ }^{-}$membranes without silver nanoparticles exhibited low gas permeation and no separation of the propylene/propane mixtures; mixed gas permeance is ca. $0.1 \mathrm{GPU}\left(1 \mathrm{GPU}=1 \times 10^{-6} \mathrm{~cm}^{3}(\mathrm{STP})\right.$ $\mathrm{cm}^{-2} \mathrm{~s}^{-1} \mathrm{cmHg}^{-1}$ ) and the selectivity of propylene/propane is nearly unity. Figure 1 shows the selectivity and total permeance of propylene over propane through $\mathrm{BMIM}^{+} \mathrm{BF}_{4}^{-}$and $\mathrm{BMIM}^{+} \mathrm{PF}_{6}^{-}$ 
membranes containing silver nanoparticles. The presence of silver nanoparticles in the $\mathrm{BMIM}^{+} \mathrm{BF}_{4}^{-}$ and $\mathrm{BMIM}^{+} \mathrm{PF}_{6}{ }^{-}$membranes resulted in an increase in both the selectivity and the permeance. It was thought that the interactions between the silver nanoparticle and the counteranion of the ionic liquid would cause the silver nanoparticles to be partially polarized, resulting in the facilitated olefin transport. The selectivity of propylene/propane and the mixed gas permeance in $\mathrm{BMIM}^{+} \mathrm{BF}_{4}{ }^{-} / \mathrm{Ag}$ membrane increased to 17 and 2.7 GPU, respectively. However, at weight ratios higher than 0.7 , the propylene permeance decreased with the increasing amount of silver metal, presumably due to the aggregation of the nanoparticles and consequently the loss of the carrier activity. Furthermore, the aggregation of Ag nanoparticles could play a role as barriers for gas transport, resulting in the decrease in gas permeance.

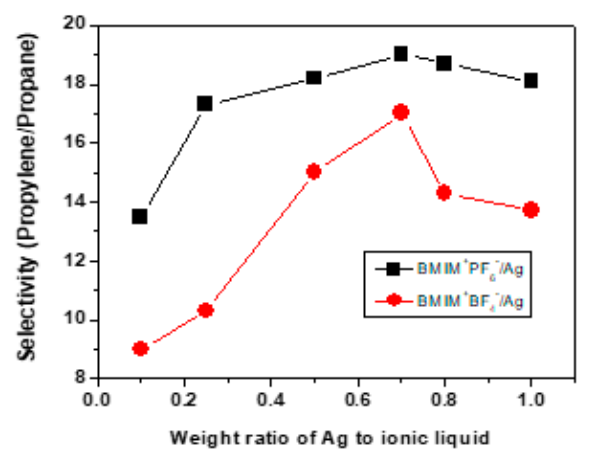

(a)

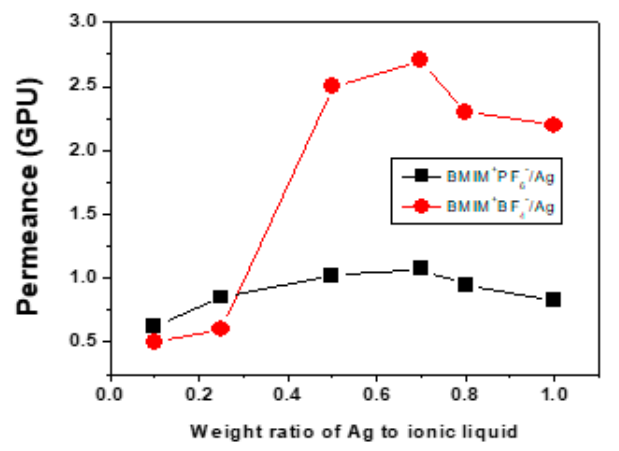

(b)

Figure 1. Separation performance: (a) mixed gas selectivity and (b) total permeance of $\mathrm{BMIM}^{+} \mathrm{BF}_{4}{ }^{-}$ and $\mathrm{BMIM}^{+} \mathrm{PF}_{6}{ }^{-}$membranes with various weight ratios of silver nanoparticles.

On the other hand, for the $\mathrm{BMIM}^{+} \mathrm{PF}_{6}{ }^{-} / \mathrm{Ag}$ membrane, the selectivity of propylene/propane and the mixed gas permeance increased to 19 and $1.1 \mathrm{GPU}$, respectively, as shown in Table 1. Interestingly, $\mathrm{BMIM}^{+} \mathrm{PF}_{6}{ }^{-} / \mathrm{Ag}$ membrane showed the higher selectivity than $\mathrm{BMIM}^{+} \mathrm{BF}_{4}{ }^{-} / \mathrm{Ag}$ membrane, even at a low silver concentration. It was thought that the interaction between $\mathrm{PF}_{6}{ }^{-}$and silver nanoparticle was stronger than that between $\mathrm{BF}_{4}{ }^{-}$and silver nanoparticle. Since the surface polarity of Ag nanoparticles increased, the reversible interaction with olefin molecules was enhanced, resulting in the increase in selectivity for propylene/propane mixtures. On the other hand, low permeance of $\mathrm{BMIM}^{+} \mathrm{PF}_{6}{ }^{-} / \mathrm{Ag}^{-}$ membrane was attributable to the hydrophobicity of $\mathrm{BMIM}^{+} \mathrm{PF}_{6}{ }^{-}$, capturing the propylene and propane molecules in ionic liquid. Furthermore, the viscosity of $\mathrm{BMIM}^{+} \mathrm{BF}_{4}{ }^{-}$was $0.0325 \mathrm{~Pa} \cdot \mathrm{s}$, while that of $\mathrm{BMIM}^{+} \mathrm{PF}_{6}{ }^{-}$was $0.05 \mathrm{~Pa} \cdot \mathrm{s}$, as shown in Table 2 . Higher viscosity of $\mathrm{BMIM}^{+} \mathrm{PF}_{6}{ }^{-}$indicated the relatively higher interactions between cations and counteranions, resulting in the diminishment of mixed-gas permeance. Thus, the hydrophobic properties and higher viscosity played a role as factors for low mixed-gas permeance.

The stability of $\mathrm{BMIM}^{+} \mathrm{BF}_{4}{ }^{-}$and $\mathrm{BMIM}^{+} \mathrm{PF}_{6}{ }^{-} / \mathrm{Ag}$ composite membranes was also tested by measuring the separation performances of propylene/propane mixtures for up to $160 \mathrm{~h}$. Figures 2 and 3 show the selectivity and mixed gas permeance with respect to propylene/propane of the $\mathrm{BMIM}^{+} \mathrm{BF}_{4}^{-}$ and $\mathrm{BMIM}^{+} \mathrm{PF}_{6}{ }^{-}$membranes containing the silver nanoparticles, respectively. The weight ratio of silver nanoparticles to ionic liquid was fixed at $1 / 0.7$. The $\mathrm{BMIM}^{+} \mathrm{BF}_{4}{ }^{-} / \mathrm{Ag}$ composite membrane showed stability up to $100 \mathrm{~h}$, but decreased after $100 \mathrm{~h}$, possibly due to the particle aggregation in the membrane. It was thought that these aggregation phenomena of $\mathrm{Ag}$ nanoparticles in $\mathrm{BMIM}^{+} \mathrm{BF}_{4}{ }^{-} \mathrm{was}^{-}$ attributable to the relatively weak interaction between the surface of the metal and the hydrophilic ionic liquid since the utilized metal had hydrophobic properties.

On the other hand, the selectivity and the permeance of $\mathrm{BMIM}^{+} \mathrm{PF}_{6}{ }^{-} / \mathrm{Ag}$ composite membrane were nearly invariant for the duration of the experiment up to $160 \mathrm{~h}$, which suggested that particles aggregation did not happen. It was supposed that the interaction between the hydrophobic $\mathrm{BMIM}^{+} \mathrm{PF}_{6}{ }^{-}$ and silver nanoparticles was stronger than that between the hydrophilic $\mathrm{BMIM}^{+} \mathrm{BF}_{4}^{-}$and silver 
nanoparticles. These favorable interactions between $\mathrm{BMIM}^{+} \mathrm{BF}_{4}{ }^{-}$and silver nanoparticles caused the metal to be maintained as non-aggregated state even under gas transport with time. From these results, the hydrophobic properties in ionic liquid-based composite membranes were more desirable for long-term stable membranes.

Table 1. Separation performance of $\mathrm{BMIM}^{+} \mathrm{BF}_{4}{ }^{-} / \mathrm{Ag}$ and $\mathrm{BMIM}^{+} \mathrm{PF}_{6}{ }^{-} / \mathrm{Ag}$ composite membranes.

\begin{tabular}{lcc}
\hline & Mixed-Gas Selectivity & Permeance (GPU) \\
\hline $\mathrm{BMIM}^{+} \mathrm{BF}_{4}{ }^{-} / \mathrm{Ag}$ & 17 & 2.7 \\
\hline $\mathrm{BMIM}^{+} \mathrm{PF}_{6}{ }^{-} / \mathrm{Ag}$ & 19 & 1.1 \\
\hline
\end{tabular}

Table 2. Properties of $\mathrm{BMIM}^{+} \mathrm{BF}_{4}^{-}$and $\mathrm{BMIM}^{+} \mathrm{PF}_{6}{ }^{-}$

\begin{tabular}{|c|c|c|}
\hline & $\mathrm{BMIM}^{+} \mathrm{BF}_{4}^{-}$ & $\mathrm{BMIM}^{+} \mathrm{PF}_{6}^{-}$ \\
\hline Chemical structure & & \\
\hline Melting point & $-80^{\circ} \mathrm{C}$ & $-8^{\circ} \mathrm{C}$ \\
\hline Solubility in water & soluble & insoluble \\
\hline Viscosity $(\mathrm{Pa} \cdot \mathrm{s})$ & 0.0325 & 0.05 \\
\hline 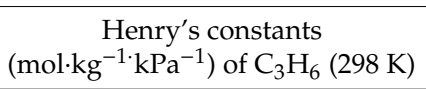 & $5.7 \cdot 10^{-4}$ & - \\
\hline
\end{tabular}

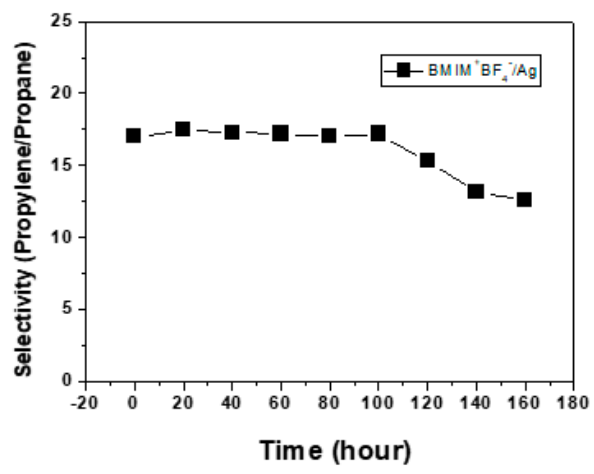

(a)

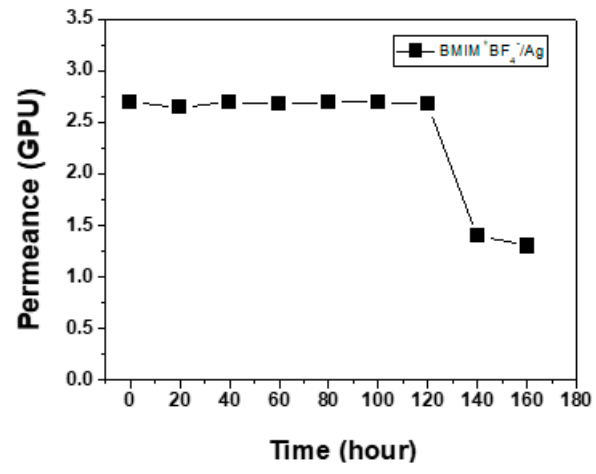

(b)

Figure 2. Separation performance: (a) mixed gas selectivity and (b) total permeance of 1/0.7 $\mathrm{BMIM}^{+} \mathrm{BF}_{4}{ }^{-} / \mathrm{Ag}$ membranes as a function of time (40 psig and $20^{\circ} \mathrm{C}$ ).

These experimental results suggest that the ionic liquids could cause a favorable interaction between the silver particles and olefin, resulting in facilitated olefin transport and improved separation performance for olefin/paraffin mixtures. In particular, the hydrophobic $\mathrm{BMIM}^{+} \mathrm{PF}_{6}{ }^{-}$ ionic liquid was more desirable for the long-term stable membrane than hydrophilic $\mathrm{BMIM}^{+} \mathrm{BF}_{4}{ }^{-}$, even though $\mathrm{BMIM}^{+} \mathrm{BF}_{4}^{-} / \mathrm{Ag}$ membranes showed higher mixed-gas permeance. These stable separation performances were related to the sustainable polarity of silver nanoparticles. Thus, the stability of polarity in silver particles was characterized in the following sections in terms of the changes in binding energy, as examined by spectroscopy. 


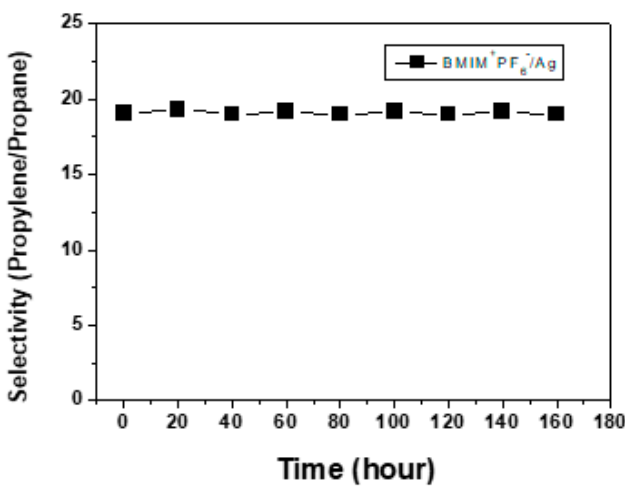

(a)

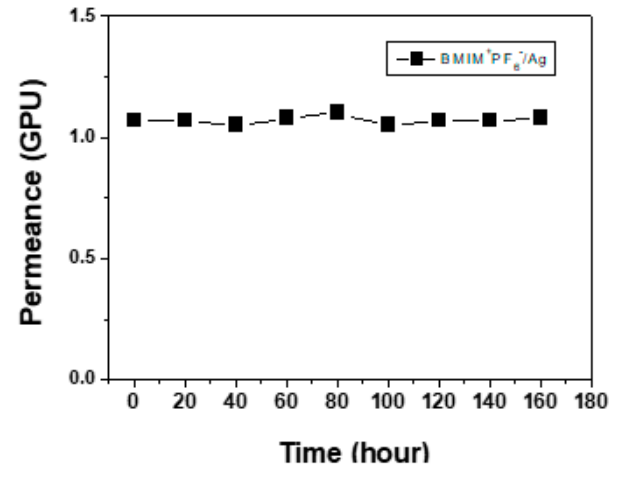

(b)

Figure 3. Separation performance: (a) mixed gas selectivity and (b) total permeance of $1 / 0.7$ $\mathrm{BMIM}^{+} \mathrm{PF}_{6}{ }^{-} / \mathrm{Ag}$ membranes as a function of time (40 psig and $20^{\circ} \mathrm{C}$ ).

\subsection{Change of Binding Energies}

X-ray photoelectron spectroscopy (XPS) was used to observe the change in the chemical environment with time around the silver nanoparticles in ionic liquid/Ag metal composite. It was well known that the $d_{5 / 2}$ orbital of $A g$ was observed at $368.26 \mathrm{eV}$ and could be shifted by a change in electron density in the metal [15]. Interestingly, the binding energy of the $d_{5 / 2}$ orbital of the silver particle in the $1 / 0.7 \mathrm{BMIM}^{+} \mathrm{BF}_{4}{ }^{-} / \mathrm{Ag}$ metal composite system increased gradually from 368.26 to $369.12 \mathrm{eV}$, as shown in Figure 4. This indicated that the binding energy of the valence electrons in the silver atoms increased due to the interactions between the silver atoms and $\mathrm{BMIM}^{+} \mathrm{BF}_{4}{ }^{-}$, and that the surface of the silver nanoparticles was partially positively charged [15]. These results indicate that the ionic liquid could change the state of electron density in the surface of Ag metal, resulting in the positive polarity on metal [15]. However, after 1 week, the binding energy of the $d_{5 / 2}$ orbital of the silver particle decreased from 369.12 to $368.56 \mathrm{eV}$ due to the phase separation, resulting in the deterioration of separation performance. As shown in Scheme 1, the Ag nanoparticles in the ionic liquid $\mathrm{BMIM}^{+} \mathrm{BF}_{4}{ }^{-}$ were stabilized and positively polarized, showing the facilitated propylene transport. However, the $\mathrm{Ag}$ nanoparticles were aggregated with time due to the relatively weak interaction between the surface of the metal and the ionic liquid, resulting in poor long-term stability.

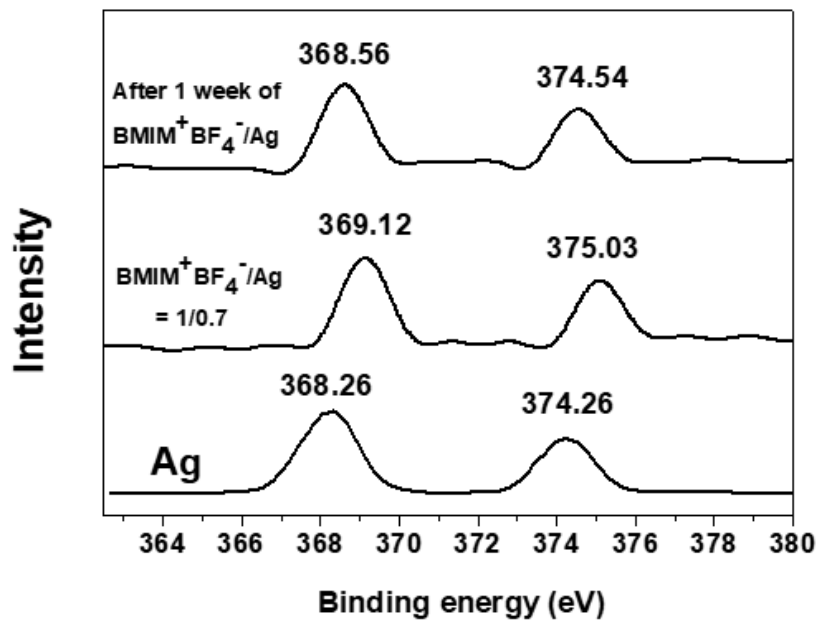

Figure 4. Binding energy of $\mathrm{Ag}$ in $1 / 0.7 \mathrm{BMIM}^{+} \mathrm{BF}_{4}{ }^{-} / \mathrm{Ag}$ composites after preparation and after 1 week. 

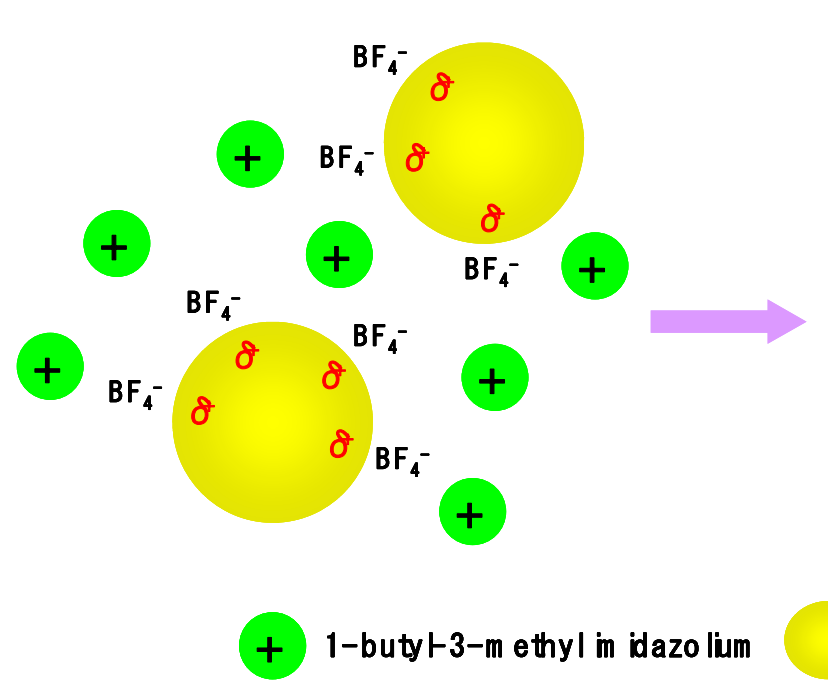

\section{1-buty -3-m ethyl in idazo lium}

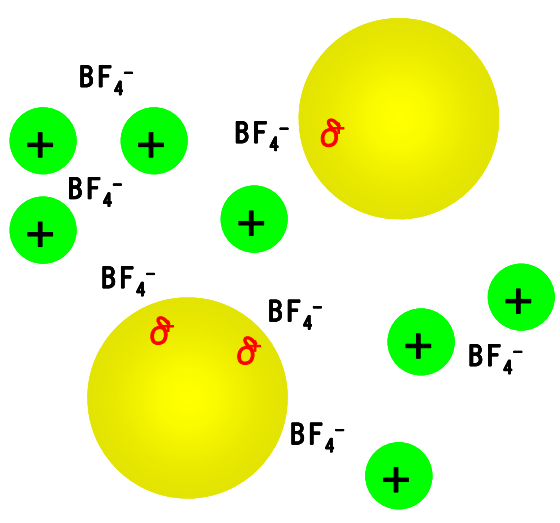

S iver nanopartic le

Scheme 1. Ag nanoparticles in ionic liquid $\mathrm{BMIMBF}_{4}$ with time.

On the other hand, the binding energy of the $d_{5 / 2}$ orbital of the silver particle in the $1 / 0.7$ $\mathrm{BMIM}^{+} \mathrm{PF}_{6}{ }^{-} / \mathrm{Ag}$ metal composite system increased gradually from 368.26 to $369.21 \mathrm{eV}$, as shown in Figure 5. The increased binding energy of Ag metal indicated the positive polarity of surface, resulting in the facilitated propylene transport. Surprisingly, the binding energy remained constant even after 1 week, indicating that the phase was not separated, as shown in Scheme 2, consistent with long-term stable separation performance.

Therefore, it can be concluded that the hydrophobic ionic liquid was more desirable than the hydrophilic ionic liquid for facilitated olefin transport membrane from the viewpoint of long-term stability.

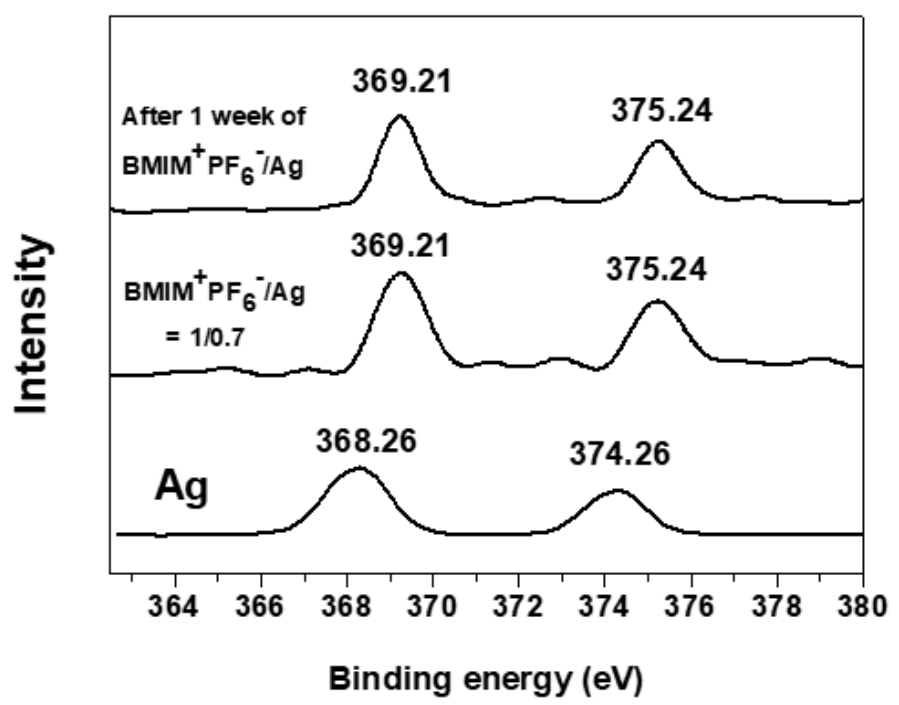

Figure 5. Binding energy of $\mathrm{Ag}$ in $1 / 0.7 \mathrm{BMIM}^{+} \mathrm{PF}_{6}{ }^{-} / \mathrm{Ag}$ composites after preparation and after 1 week. 


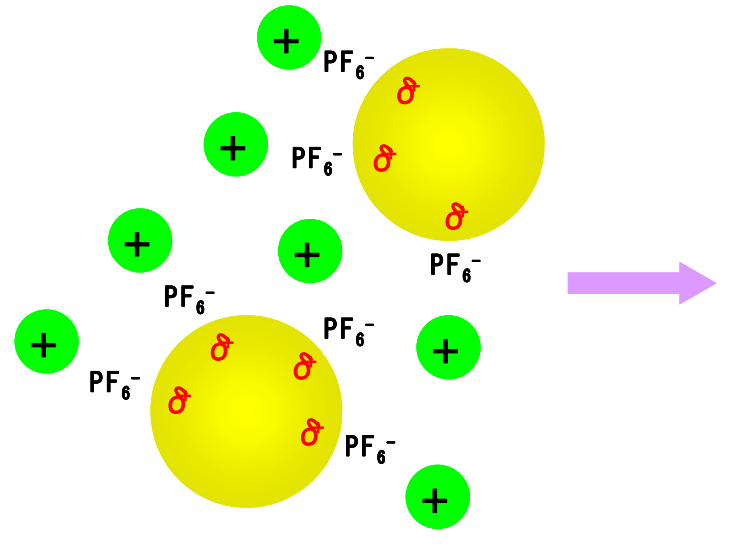

+ 1-buty $1-3-m$ ethyl in idazo lium

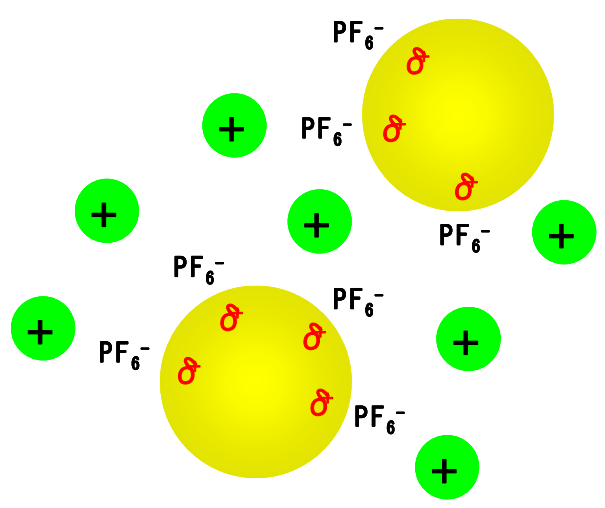

S iver nanopartic le

Scheme 2. Ag nanoparticles in ionic liquid $\mathrm{BMIMPF}_{6}$ with time.

\section{Conclusions}

In summary, we succeeded in preparing for the long-term stable composites consisting of $\mathrm{BMIM}^{+} \mathrm{PF}_{6}{ }^{-}$and $\mathrm{Ag}$ metal for liquid-based membranes. $\mathrm{BMIM}^{+} \mathrm{PF}_{6}{ }^{-} / \mathrm{Ag}$ nanocomposite membranes showed long-term stability for more than $160 \mathrm{~h}$, while the deterioration of separation performance in $\mathrm{BMIM}^{+} \mathrm{BF}_{4}^{-} / \mathrm{Ag}$ nanocomposite membranes was observed. In fact, the binding energy of Ag metal in $\mathrm{BMIM}^{+} \mathrm{PF}_{6}{ }^{-}$remained constant even after 1 week due to a strong interaction between the surface of $\mathrm{Ag}$ and ionic liquids. The separation performance and the XPS data indicated that the hydrophobic $\mathrm{BMIM}^{+} \mathrm{PF}_{6}{ }^{-} / \mathrm{Ag}$ metal composite membrane was more stable than hydrophilic $\mathrm{BMIM}^{+} \mathrm{BF}_{4}{ }^{-} / \mathrm{Ag}$ metal composite membrane, since the surface of silver metal was hydrophobic, resulting in the long-term stable attraction between ionic liquid and surface of nanoparticles. From these results, we could suggest the crucial factor for long-term stability in liquid-based membranes.

Author Contributions: S.W.K. led the project, performed the experiments, collected the data and wrote the manuscript. All authors have read and agreed to the published version of the manuscript.

Funding: This work was supported by the Basic Science Research Program (2020R1F1A1048176) through the National Research Foundation of Korea (NRF), funded by the Ministry of Science, ICT, and Future Planning. This work was supported by the National Research Council of Science \& Technology (NST) grant by the Korea government (MSIT) (No. CRC-14-1-KRICT).

Conflicts of Interest: The authors declare no conflict of interest.

\section{References}

1. Sunderrajan, S.; Freeman, B.D.; Hall, C.K.; Pinnau, I. Propane and propylene sorption in solid polymer electrolytes based on poly(ethylene oxide) and silver salts. J. Membr. Sci. 2001, 182, 1. [CrossRef]

2. Hamid, M.R.A.; Jeong, H.-K. Recent advances on mixed-matrix membranes for gas separation: Opportunities and engineering challenges. Korean J. Chem. Eng. 2018, 35, 1577. [CrossRef]

3. Kim, S.Y.; Cho, Y.; Kang, S.W. Preparation and characterization of PEBAX-5513/AgBF4/BMIMBF4 membranes for olefin/paraffin separation. Polymers 2020, 12, 1550. [CrossRef] [PubMed]

4. Zarca, R.; Ortiz, A.; Gorri, D.; Ortiz, I. A practical approach to fixed-site-carrier facilitated transport modeling for the separation of propylene/propane mixtures through silver containing polymeric membranes. Sep. Purif. Tech. 2017, 180, 82. [CrossRef]

5. Kim, S.Y.; Cho, Y.; Kang, S.W. Correlation between functional group and separation performance in PEBAX/Ag salt/Al salt complexes for olefin separation. Polymers 2020, 12, 667. [CrossRef] [PubMed]

6. Jung, K.W.; Kang, S.W. Effect of functional group ratio in PEBAX copolymer on separation performance for facilitated olefin transport membranes. Sci. Rep. 2019, 9, 11454-11459. [CrossRef] [PubMed] 
7. Jeon, H.; Kang, S.W. Hybrid effect of Ag ions and polarized Ag nanoparticles in poly(ethylene oxide)/AgBF4/ionic liquid composites for long-term stable membranes. Polym. Compos. 2019, 40, 2745. [CrossRef]

8. Lee, J.H.; Sudhager, P.; Cho, Y.; Kang, S.W. Effect of temperature on separation performance in ionic liquid/Ag nanocomposite membranes for olefin/paraffin mixtures. J. Ind. Eng. Chem. 2019, 74, 103. [CrossRef]

9. Jeon, H.; Kang, S.W. Poly(ethylene oxide)/Ag ions and nanoparticles/1-hexyl-3-methylimidazolium tetrafluoroborate composite membranes with long-term stability for olefin/paraffin separation. RSC Adv. 2019, 9, 4771. [CrossRef]

10. Wang, K.; Stiefel, E.I. Toward Separation and Purification of Olefins Using Dithiolene Complexes: An electrochemical Approach. Science 2001, 291, 106. [CrossRef] [PubMed]

11. McKenna, M.; Wright, L.L.; Miller, D.J.; Tanner, L.; Haltiwanger, R.C.; DuBois, M.R. Synthesis of inequivalently bridged cyclopentadienyl dimers of molybdenum and a comparison of their reactivities with unsaturated molecules and with hydrogen. J. Am. Chem. Soc. 1983, 105, 5329. [CrossRef]

12. Chae, I.S.; Kang, S.W.; Park, J.Y.; Lee, Y.G.; Lee, J.H.; Won, J.; Kang, Y.S. Surface energy level tuning of silver nanoparticle for facilitated olefin transport. Angew. Chem. Intern. Edit. 2011, 123, 3038-3041. [CrossRef]

13. Hong, G.H.; Song, D.; Chae, I.S.; Oh, J.H.; Kang, S.W. Highly permeable poly(ethylene oxide) with silver nanoparticles for facilitated olefin transport. RSC Adv. 2014, 4, 4905. [CrossRef]

14. Kim, M.; Kang, S.W. PEBAX-1657/Ag nanoparticles/7,7,8,8-tetracyanoquinodimethane complex for highly permeable composite membranes with long-term stability. Sci. Rep. 2019, 9, 4266. [CrossRef] [PubMed]

15. Kang, S.W.; Char, K.; Kang, Y.S. Formation of Partially Positively Charged Surface of Silver Nanoparticles by Ionic Liquid and Application for Facilitated Olefin Transport Membrane for Olefin/Parffin Separation. Chem. Mater. 2008, 20, 1308-1311. [CrossRef]

(C) 2020 by the author. Licensee MDPI, Basel, Switzerland. This article is an open access article distributed under the terms and conditions of the Creative Commons Attribution (CC BY) license (http://creativecommons.org/licenses/by/4.0/). 